\title{
Low Dose of Azithromycin Enhances the Anticancer Efficacy of Sorafenib in HepG2 Cell Line
}

\author{
Dabeeran Zehra ${ }^{1}$, Zahida Memon ${ }^{1}$, Shumaila Usman ${ }^{2, *}$, Almas Jabeen ${ }^{3}$, \\ Kauser Ismail ${ }^{1}$ and Rehan Ahmed Siddiqui ${ }^{2}$ \\ ${ }^{1}$ Department of Pharmacology, Ziauddin University, Karachi \\ ${ }^{2}$ Department of Research, Ziauddin University, Karachi \\ ${ }^{3}$ Dr. Panjwani Centre for Molecular Medicine and Drug research, International Centre \\ for Chemical and Biological Sciences, Karachi
}

\begin{abstract}
A B S T R A C T
Sorafenib, a multi kinase inhibitor, is the only FDA approved drug designed to target advanced hepatocellular carcinoma (HCC). However, unbearable side effects, insufficient efficacy and resistance mechanisms against this drug, generates necessity to develop novel therapeutic strategies and drugs. Recently macrolides have drawn attention of researchers in the treatment of cancer owing to their proposed chemotherapeutic role, based on the concept of repurposing, as they are well tolerated, less toxic and inexpensive. In this study we evaluated the combine effects of low dose of Azithromycin with Sorafenib in HepG2 cell line. Co-treatment of Sorafenib and Azithromycin showed enhanced inhibition of cell growth and suppressed the MAPK pathway associated with cellular proliferation, however the effects on cellular apoptosis were found to be insignificant.
\end{abstract}

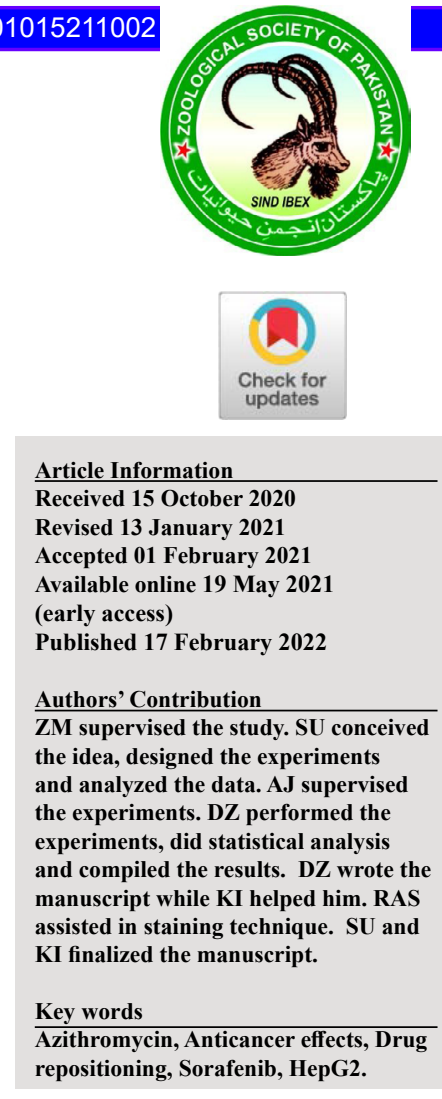

\section{INTRODUCTION}

S orafenib, an oral multi kinase inhibitor is the only FDA approved drug for advanced HCC employed to increase the survival of patients (Chen et al., 2010b). It is bi-aryl urea (Chen et al., 2010a; Le Grazie et al., 2017) that hinders tumor proliferation and angiogenesis by inhibiting several kinases involved in the MAPK pathway, the Pro inflammatory pathway involved in pathogenesis of HCC, where it specifically targets Raf-1 and B-Raf and receptor tyrosine kinase activity of vascular endothelial growth factor receptors (VEGFRs) 1, 2, and 3 along with plateletderived growth factor receptor $\beta$ (PDGFR- $\beta$ ) (Llovet et al., 2008). As MAPK pathway is more often over activated in HCC, Sorafenib is drug of choice for this cancer with Raf-1 being the target molecule (Gauthier and Ho, 2013). Monotherapy with Sorafenib is generally well tolerable, however certain adverse effects including diarrhea and hand-foot skin reaction are common. Other side effects noticed in various trials occurring variably are anorexia, alopecia, abdominal pain, dry skin, weight loss, voice changes and other dermatological events (Keating and Santoro, 2009). Apart from that, there are certain clinical trials which documented non responsiveness of Sorafenib

\footnotetext{
* Corresponding author: shumaila.usman@zu.edu.pk 0030-9923/2022/0003-1143 \$ 9.00/0

Copyright 2022 Zoological Society of Pakistan
}

(Zhu et al., 2014). Since the knowledge of underlying mechanistics involving etiology, progression and spread of cancer extend spectacularly in last four decades, different root causes of cancer resistance are continuously being explored that subsequently leads to the unearthing and development of novel approaches customized to hamper cancer resistance (Zhu et al., 2017). In this regard, studies have been conducted to understand the mechanisms of resistance against sorafenib in resistant cells which showed higher expression of different intermediates of various proliferative or pro inflammatory pathways that contributes to acquired resistance to sorafenib. These pathways in some way are also associated with HCC progression and run parallel to ERK/MAPK pathway (Zhai and Sun, 2013). Over activation of PI3K/Akt and MAPK pathway in Sorafenib resistant tested HCC cells (van Malenstein et al., 2013), tumor hypoxic environment (Liang et al., 2013), aberrant activation of EGFR receptors (Blivet-Van Eggelpoël et al., 2012), nuclear factor kappa b and autophagy (Zhai and Sun, 2013) are some of the mechanisms intricated with sorafenib resistance. Therefore, there is an utmost need to explore new strategy which could be used to reduce drug related adverse effects or/and to overcome resistance against sorafenib. For long, combination therapy is considered as the cornerstone of cancer management (Mokhtari et al., 2017) where two or more drugs with different mechanisms and toxicity profiles are usually combined in order to combat dilemma 
associated with cancer chemotherapy i.e. resistance and drug withdrawal owing to adverse effects. Combination therapy is known to improve long term prognosis and decreases side effects by modulating different molecular pathways which in turn enhances the therapeutic effect and overcome phenomena of resistance (Greco and Vicent, 2009). Combination can be beneficial in other ways, unlike a high dose of single chemotherapeutic agent which could be significantly toxic and immunosuppressant ultimately weakening the host defenses (Partridge et al., 2001) combination therapy decreases the toxicities of individualized drugs meaningfully as the combination works in a synergistic or additive manner at less therapeutic dosage for each drug (Mokhtari et al., 2013). In some of the cases combination therapy is also expected to prevent lethal effects of principle drug on normal cells while rendering the cancer to cytotoxic effects like in case of methotrexate and leucovorin combination (Ferdousi et $a l ., 2017)$. More recently combination therapy with novel drugs are being considered for targeting cancer inducing and cancer sustaining pathways, based on the phenomena of repurposing having therapeutic values for different diseases other than the cancer. Drug repositioning is an efficient approach suggesting use of FDA-approved drugs for the treatment of cancer with known pharmacological profile. Moreover sometimes combination of drugs are acquired to increase the half-life (Bell et al., 2008) or accumulation of drugs at the target sites (Gupta and Vyas, 2007) by utilizing the strategy of enzyme or efflux pump inhibition (Csoti et al., 2019; Pule et al., 2016), respectively. Recently combination therapy with novel drugs are being considered for targeting cancer inducing and sustaining pathways, based on the phenomenon drug repositioning which is an efficient approach, suggesting the use of FDA approved drugs for the treatment of cancer having known pharmacokinetic and pharmacodynamic profiles for other diseases. Recently acetazolamide (Islam et al., 2016), metformin (Safe et al., 2018), macrolides (Hirasawa et al., 2016), have been tailored for treating certain cancers not merely as solo agent but as adjuvant too (Chen et al., 2015). Azithromycin (AZM) is a semi synthetic macrolide with a 15-membered macrolactam ring structure which is also termed as azalide. It is obtained by chemical modification of macrocyclic lactone ring of erythromycin that acts by inhibition of bacterial protein synthesis at $50 \mathrm{~S}$ ribosome subunit. Though AZM gives coverage to both aerobic and anaerobic gram negative and Gram positive bacteria it is found to be more active against gram negative bacteria (e.g., Haemophilus influenza and M. catarrhalis), as well as atypical respiratory organisms (e.g., Chlamydia, Mycoplasma, Listeria, Pneumocystis, and Legionella spp.), making it broadly prescribed for the treatment of respiratory tract infections. AZM claims excellent safety profile with minimal adverse effects and once daily dosing schedule owing to relatively longer half-life (Muniz et al., 2013). Apart from its well-known antimicrobial effects, Azithromycin has been emerged as a potent anti-inflammatory, immunomodulatory and antirhinoviral agent (Zimmermann et al., 2018). Currently researchers are interested in repositioning of Azithromycin as potent anticancer agent either as adjuvant or in unaided form (Al-Darraji et al., 2018).

On the other hand, hepatoma is ranked as the fifth most common cancer globally and stands at second position in relation to cancer associated mortality (Hepatology, 2018). Around 78,200 new cases are being diagnosed every year and this incidence is expected to peak around in 2030 (Omata et al., 2017) owing to increasing chronic Hep B or $\mathrm{C}$ infection which is a dominant risk factor worldwide (Wallace et al., 2015). At early stages, surgical resection of the tumor, liver transplantation and ablative therapies are the different treatment options, while pharmacological treatment i.e. Sorafenib is the last hope for advanced disease designed to increase the mean survival of patients (Chen et al., 2010b). Keeping in view the above mentioned growing incidence of HCC cases, non-responsiveness of Sorafenib and impending advantages of AZM, this invitro study is designed to explore the anticipated amplified response of Sorafenib in the presence of low dose of AZM in the battle against HCC.

\section{METHODOLGY}

\section{Drug/compound preparation}

Test drug (Azithromycin) was purchased from Hebei Dongfeng Pharmaceutical Co. Ltd., while Sorafenib was purchased from MedChemExpress (USA). Stock concentrations of drugs were prepared in sterile $100 \%$ DMSO and were kept at $-20^{\circ} \mathrm{C}$. The working solutions of drugs were freshly prepared from stock solutions by diluting the stock in Dulbecco modified Eagle medium (DMEM). Cells were treated with different working concentrations of Sorafenib and combination of Sorafenib and Azithromycin after optimization so that their combined effect could be evaluated.

\section{Cell cultures}

Human hepatocellular cell line (HepG2) was kindly provided from PCMD (Panjwani Center for Molecular Medicine and Drug Research) Karachi, Pakistan. Cells were cultured in T75 flask in DMEM (Sigma Chemicals) supplemented with $1 \%$ penicillin and streptomycin $1 \%$, $1 \%$ L-glutamine and $10 \% \mathrm{FBS}$ in humidified atmosphere at $37^{\circ} \mathrm{C}$ containing $5 \% \mathrm{CO}_{2}$. Once reached $80 \%$ confluency, 
cells were detached using $0.05 \%$ trypsin and counted using trypan blue on hemocytometer slide under an inverted microscope.

\section{MTT cytotoxic assay}

Cytotoxicity of Sorafenib and its combination with AZM was assessed by using standard MTT colorimetric assay. Initially exponentially growing cells $(30,000$ cells/ well) were seeded in 96-wells flat bottom cell culturetreated plate in complete DMEM. Cells were given incubation for $24 \mathrm{~h}$ followed by removal of media, $200 \mu \mathrm{L}$ of fresh medium was added along with five different concentrations of Sorafenib $(0.625 \mu \mathrm{g} / \mathrm{ml}, 1.25$ $\mu \mathrm{g} / \mathrm{ml}, 2.5 \mu \mathrm{g} / \mathrm{ml}, 5 \mu \mathrm{g} / \mathrm{ml}, 10 \mu \mathrm{g} / \mathrm{ml})$ and its combination with AZM $(0.625 \mu \mathrm{g} / \mathrm{ml}, 1.25 \mu \mathrm{g} / \mathrm{ml}, 2.5 \mu \mathrm{g} / \mathrm{ml}, 5 \mu \mathrm{g} / \mathrm{ml}$, $10 \mu \mathrm{g} / \mathrm{ml}$ ) in triplicates. Treated cells were incubated in a humidified incubator with $5 \% \mathrm{CO}_{2}$ at $37^{\circ} \mathrm{C}$. After $48 \mathrm{~h}$ of treatment, media was aspirated and $50 \mu \mathrm{L}$ of MTT dye $(0.5 \mathrm{mg} / \mathrm{mL})$ was added in each well and the plate was further incubated for $4 \mathrm{~h}$. Afterwards, DMSO was added to solubilize formazan crystals, the extent of MTT reduction to formazan within cells was calculated by measuring absorbance at $570 \mathrm{~nm}$ using microplate reader (Spectra Max plus, Molecular devices, CA, USA) as described (Luo et al., 2010). The cytotoxicity exerted by compounds was recorded as concentration causing 50\% growth inhibition (IC50) for HepG2 cells.

\section{Nuclear condensation}

HepG2 cells $(30,000$ cells per well/24 well plate) were analyzed for nuclear fragmentation after being treated with Sorafenib and its combination with AZM. Cells were grown and treated with test compound for 48 $\mathrm{h}$ as described. After incubation cells were fixed with $4 \%$ paraformaldehyde, washed with PBS, and then stained with the fluorescent binding dye DAPI (4,6-diamidino-2phenylindole). Cells were then visualized under flouroscent microscope (Nikon, Japan) (DeCoster, 2007). Nuclear area factor which is circulatory $4 \mathrm{pi}\left(\right.$ area/perimeter ${ }^{2}$ ) and roundness (perimeter2)/ ( $4 *$ pi*area) was calculated after processing the images by Image J software as described.

\section{Real time RT-mRNA expression}

RNA was isolated from the treated HepG2 cells ( 1 million cells per well/6 well plate) by the TRIzol method, as per manufacturer's instructions. The concentration and purity of RNA was analysed by using NanoDrop 2000, Thermo Scientific USA. Quantification of purified RNA was done by measuring the absorbance at $260 \mathrm{~nm}$. RNA ( $1 \mu \mathrm{g})$ was used for cDNA synthesis by using Thermo scientific Revert Aid First Strand cDNA Synthesis kit. Real time PCR of cDNA samples was performed by using Thermo Scientific
Maxima Sybr Green/ROX qPCR Master Mix (2X), Each sample was run in triplicate and GAPDH was used as the normalizing control. Primers for Raf-1, MAPK3 and GAPDH are listed in Table I. The real time PCR data was analysed using the $2^{-\Delta \Delta C T}$ relative quantization method following the manufacturer's instructions. Thermocycler conditions were comprised of an initial activation step at $95^{\circ} \mathrm{C}$ for $10 \mathrm{~min}$, followed by $95^{\circ} \mathrm{C}$ for $30 \mathrm{sec}, 60^{\circ} \mathrm{C}$ for min for 40 cycles. Comparative CT method was used to calculate the fold change in gene expression (Luo et al., 2010).

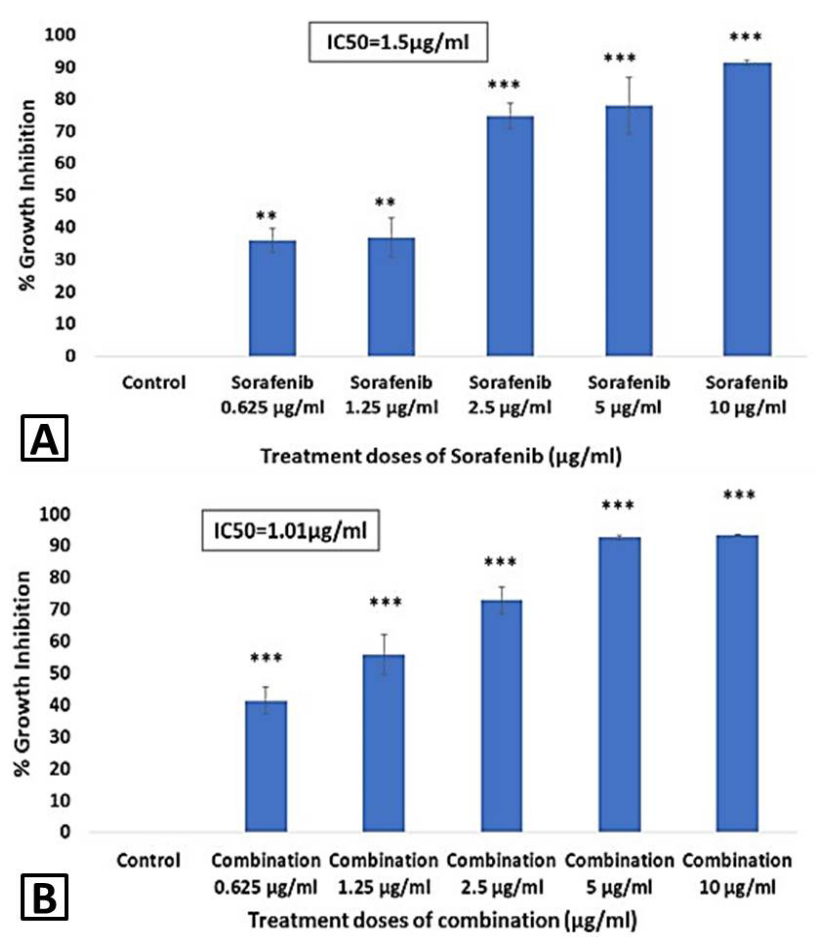

Fig. 1. Cytotoxic effects of Sorafenib and combination on HepG2 cells following $48 \mathrm{~h}$ of treatment. A, the graph shows dose dependent inhibitory effect of Sorafenib on growth of HepG2 cells. Significant difference between untreated and Sorafenib treated cells was observed and is indicated as $* * \mathrm{P}<0.01$ at $0.625 \mu \mathrm{g} / \mathrm{ml}$ and $1.25 \mu \mathrm{g} / \mathrm{ml}$, and $* * * \mathrm{P}<0.001$ at higher doses. $\mathrm{B}$, bar graph shows dose dependent effect of combination on growth inhibition of HepG2 cells with level of significance $* * * \mathrm{P}<0.001$ versus untreated group. Each bar represents mean \pm SEM for the experiments run in triplicates.

\section{Statistical analysis}

SPSS program (version 20) was used for analysis of data. All numerical values were presented as mean \pm S.E. of mean (SEM). The mean and SEM of the treatment group was generated by ANOVA (Analysis of variance). To find comparison between the groups, Tukey's post hoc 
tests were applied. The significant difference between and within the treatment groups was considered significant at set P-value $<0.05$.

\section{RESULTS}

\section{Cytotoxicity of Sorafenib HepG2}

We have tested the effects of Sorafenib alone and combination of Sorafenib with Azithromycin (AZM) against hepatocellular cancer (HepG2) cell line. Cytotoxic analysis was done via MTT for both treatment groups at different concentrations. The concentrations tested for Sorafenib and combination were attained after the procedure of optimization. Sorafenib showed inhibition of proliferation at $0.625 \mu \mathrm{g} / \mathrm{mL}, 1.25 \mu \mathrm{g} / \mathrm{mL}$ with p-value $(<0.01)$ and at $2.5 \mu \mathrm{g} / \mathrm{mL}, 5 \mu \mathrm{g} / \mathrm{mL}$ and $10 \mu \mathrm{g} / \mathrm{mL}$ the p-value was $<0.001$ (Fig. 1A) while combination showed highly significant cytotoxicity at all concentrations with P-value $(<0.001)$ (Fig. 1B). The IC50 calculated for Sorafenib was $1.5 \mu \mathrm{g} / \mathrm{mL}$ and was decreased for combination treatment i.e. $1.01 \mu \mathrm{g} / \mathrm{mL}$.

\section{Effect on cell Morphology}

The effect of Sorafenib and combination on morphology of HepG2 was studied under inverted phase microscope. After $48 \mathrm{~h}$ of treatment with Sorafenib and combination at their IC50 concentrations, cells showed morphological alteration as compare to control (Fig. 2).

\section{Table I.- The primer sequence for quantitative real time PCR.}

\begin{tabular}{llcc}
\hline Gene & Gene name & \multicolumn{2}{c}{ Primer sequence } \\
\cline { 3 - 4 } & & Forward & Reverse \\
\hline GAPDH & Glyceraldehyde-3 Phosphate Dehydrogenase & CCAGAACATCATCCCTGCCT & CCTGCTTCACCACCTTCTTG \\
MAPK3 & Mitogen-Activated Protein Kinase 3 & GGCCCGAAACTACCTACAGT & CGTCGGGTCATAGTACTGCT \\
RAF1 & Raf-1 Proto-Oncogene, Serine/Threonine Kinase & CAACCCCAGAGCAATTCCAG & AGGTGTTTGTAGAGGCTGCT \\
\hline
\end{tabular}
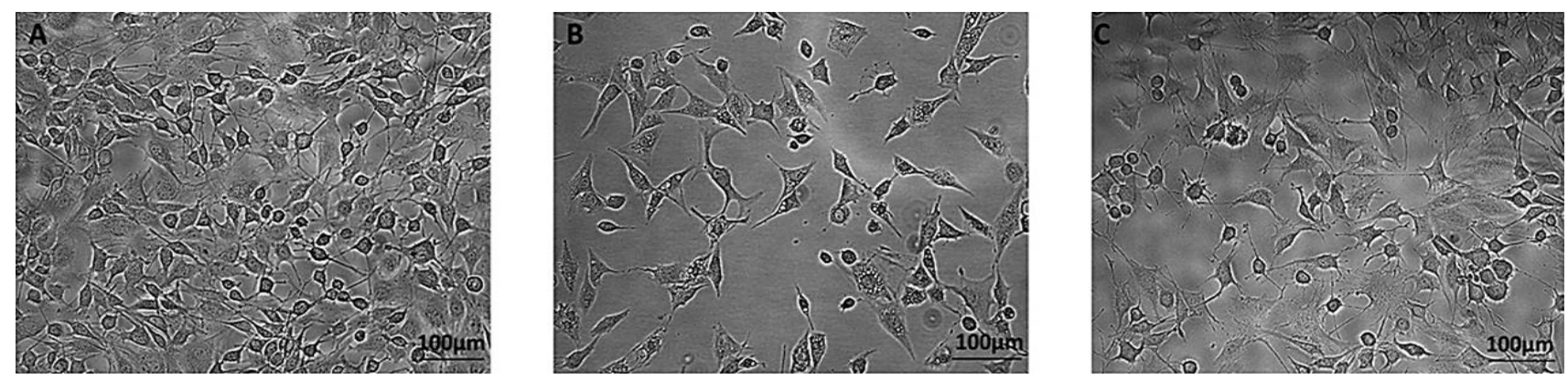

Fig. 2. Inverted phase microscopy showing HepG2 cells control (A), Sorafenib (B) and combination (C) treated cells. The control cells (A) display normal morphology of HepG2 cells. In contrast, the cells treated with sorafenib (B) and combination (C) at their IC50 concentrations showed morphological alteration as compared to control. Images were taken at 10X magnification and scale bar is $100 \mu \mathrm{m}$.
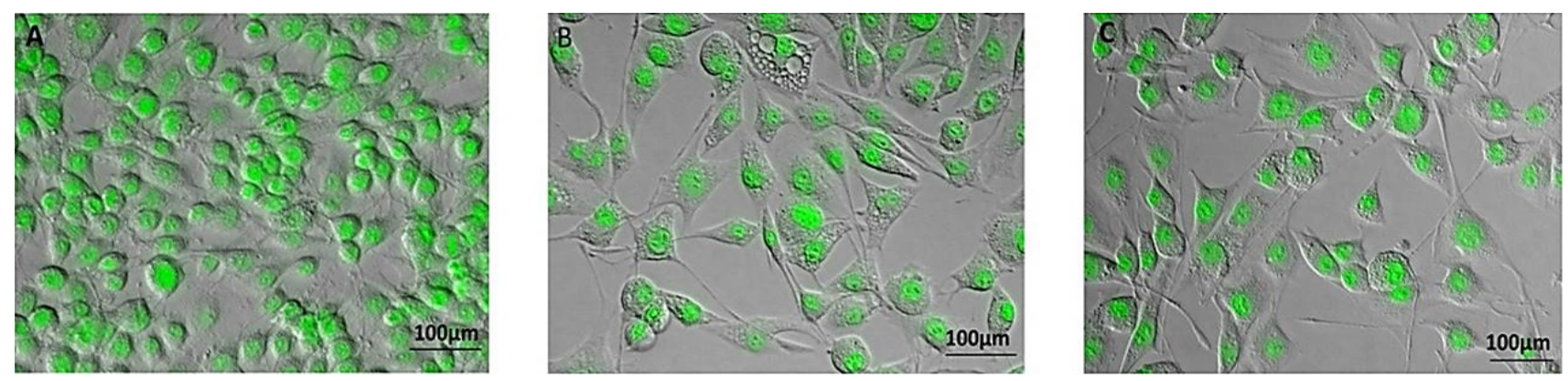

Fig. 3. Fluorescence microscopy showing DAPI stained nuclei of HepG2 control (A), Sorafenib (B) and combination (C) treated cells depicting insignificant results. Fluorescence microscopy was done at $10 \mathrm{X}$ magnification. Scale bar was $100 \mu \mathrm{m}$. 


\section{Effect of Sorafenib on apoptosis of HepG2}

The effect of Sorafenib and combination on apoptosis was studied by performing DAPI staining. Disintegration of nuclei and reduction in nuclear area factor are morphological markers of apoptosis. After $48 \mathrm{~h}$ of treatment with Sorafenib and combination at their IC50 concentrations, HepG2 cells were observed for nuclear condensation (Fig. 3) and for reduction in nuclear area factor (Fig. 4) which showed insignificant effects.

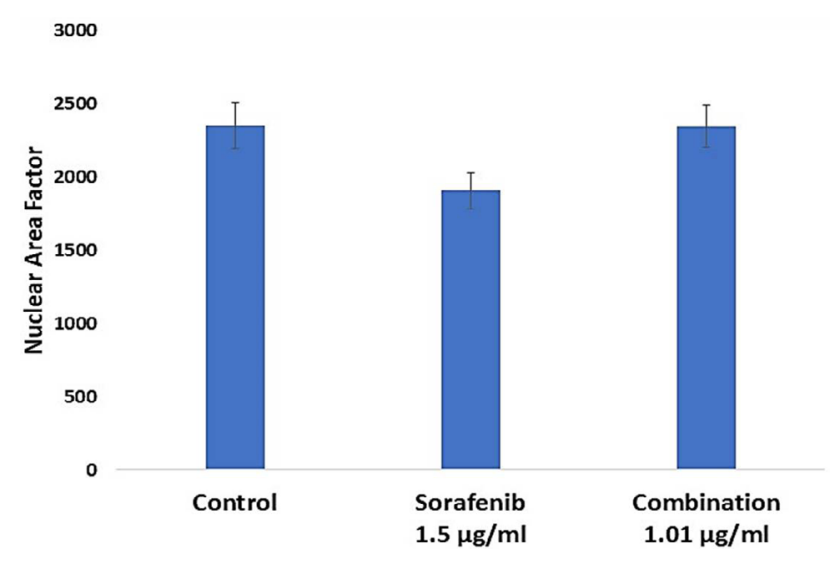

Fig. 4. Analysis of nuclear area factor after Sorafenib and combination treatment induced apoptosis in DAPI stained HepG2 cells. ImajeJ software was used for calculating circularity $4 \mathrm{pi}\left(\right.$ area/perimetre $\left.{ }^{2}\right)$ and roundness $\left(\right.$ perimeter $\left.^{2}\right) /$ $\left(4 * \mathrm{pi}^{*}\right.$ area). Nuclear area factor was calculated as the product of object area (in pixels2)*roundness. Data was presented as mean \pm SEM and experiments were run in triplicates.

\section{Effect of Sorafenib on expression of Raf-1 and MAPK3}

qRT-PCR analysis was performed to determine the effects of Sorafenib and combination on the expression of genes (RAF-1 and MAPK3) which showed highly significant $(* * * \mathrm{P}<0.001)$ downregulation of RAF-1 by both the groups at their IC50 concentrations. MAPK3 expression was also significantly decreased after Sorafenib $(* * * \mathrm{P}<0.001)$ and combination treatment $(* \mathrm{P}<0.05)$.

\section{DISCUSSION}

Macrolides are recently being considered for the development of novel chemotherapeutic agents or as an adjuvant to traditional anticancer drugs in the treatment of various carcinomas (Zehra et al., 2019). Azithromycin, one of the safest macrolide has been studied in combination with recommended anticancer drugs for their anticipated synergistic activity previously in colon (Qiao et al., 2018), cervical and gastric cancer (Zhou et al., 2012). Further its role in overcoming resistance generated by chemotherapeutic agents has also been appreciated (Asakura et al., 2004). Therefore, considering the usefulness of this drug we explored its synergistic anticancer role against hepatoma cell line.

We initially analyzed its cytotoxic activity of Sorafenib alone and in combination with low dose of Azithromycin on HepG2 cell line for $48 \mathrm{~h}$ where we found more significant results with later treatment. A study supporting our results conducted with combination Vincristine (VCR) and AZM via MTT on Hela and SGC7901 cells by Zhou et al showed significant inhibition in both cancer cell lines in time and dose dependent manner indicating that their combination was more effective in inhibiting the proliferation of cancer cells when compared to Vincristine alone (Zhou et al., 2012).

In the same study, the effects of AZM alone and in combination were also studied in non-cancer cell line i.e. BHK-21 (a transformed hamster fibroblast cell line) in which AZM or combination showed no significant cytotoxicity proving the safety of AZM in normal cells (Zhou et al., 2012).

Another study done on colon cancer cell lines (SW480, HCT-116), AZM alone and in combination with TRAIL showed significant cell death by combination treatment when analyzed by annexin V-FITC/PI staining detected by flowcytometry (Qiao et al., 2018).

Others macrolides along with Azithromycin (AZM) i.e., Erythromycin (EM) and Clarithromycin (CAM) were also studied by Moriya et al on multiple myeloma cell lines (U266, IM-9 and RPMI8226) both alone and in combination with Bortezomib (BZ). It was also noted that AZM, CAM or erythromycin alone showed no cytotoxicity up to $100 \mu \mathrm{g} / \mathrm{mL}$ in $\mathrm{MM}$ cell lines while the combination of AZM at 25 and $50 \mu \mathrm{g} / \mathrm{mL}$ with bortezomib enhanced the BZ-induced cytotoxicity which suggests the use of macrolide antibiotic as adjuvant for MM therapy. Further, it was stated that the cytotoxicity by combination is based on two major intracellular protein degradation systems such as ubiquitin-proteasome system inhibition by bortezomib and the autophagy-lysosome system suppression by macrolides which together enhanced endoplasmic reticulum mediated apoptosis in MM cells (Moriya et al., 2013).

Apart from Macrolide's antibiotics ability to restrain autophagy, another supposed mechanism of their cytotoxicity is inhibition of mitochondrial biogenesis which is the fundamental requirement of cancer stem cells for their survival (Lamb et al., 2015). This side effect of antibiotics of inhibiting mitochondrial biogenesis could be connected to the therapeutic effects in terms of anticancer potential. AZM came out as inhibitor of mitochondrial biogenesis in this study (Lamb et al., 2015). 
We also performed q-PCR to confirm our results and to inquest the underlying molecular effects of combined therapy. The molecular basis for the anticancer mechanism was assessed via testing the effects of these drugs (at IC50 concentrations) on regulation of genes (RAF1 and MAPK3) involved in MAPK proliferative pathway (Pang et al., 2012).

Sorafenib is renowned for its inhibitory effects on MAPK pathway therefore it was expected to obtain highly significant down regulation of both RAF and MAPK genes (Carlo-Stella et al., 2013; Gedaly et al., 2012) (Fig. 5).

While for combination, unlike Sorafenib alone we didn't get much significant downregulation of MAPK3 gene ( $p$ value $<0.05$ ) when compared to Sorafenib (Fig. 5), despite of highly significant Raf down regulation ( $\mathrm{p}$ value $<0.001$ ) (Fig. 5) and low IC50 value for cytotoxicity $(1.01 \mu \mathrm{gm} / \mathrm{ml})$.

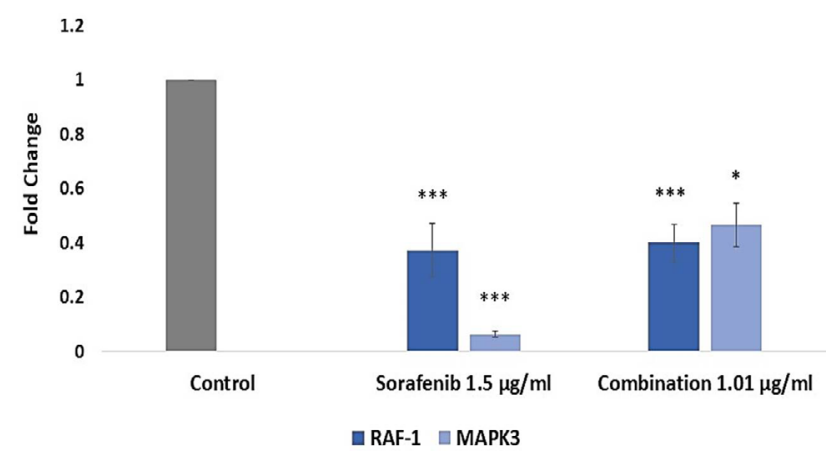

Fig. 5. Down regulation of mRNA expression of RAF1 and MAPK3 after being treated with sorafenib and combination at their IC50 concentrations. GAPDH was used as control gene. Fold change was calculated by $\Delta \mathrm{Ct}$ method after obtaining CT values. The data was presented as mean \pm SEM of three independent experiments.

The possible explanation behind this surprising finding is a drug combination could be different from individual constituent and may act likely in one of the three ways i.e. it may homogenize individual drug mechanism, it may create a novel binding site; not present in individual drugs, or it may behave as totally original molecule (Pritchard et al., 2013).

Apart from that, there are multiple cross talks at level of Raf, therefore it is possible that likely structural/ chemical modifications in combined dosage form may inhibit other ERK independent pathways.

In this regard MAPK independent, different cross links of Raf (Feng et al., 2017) have been reported which showed the interaction of Raf- 1 with $\mathrm{Rb}$ and $\mathrm{p} 130$ proteins in vitro, which is pivotal step in the growth factor-mediated induction of cell proliferation (Wang et al., 1998).
Another crosstalk exists at the level of Raf with PIKt3/ Akt Pathway. Akt is found to interact with Raf and bring about its phosphorylation which inhibits the activation of Raf-MEK-ERK (Zimmermann and Moelling, 1999).

Apart from above mentioned cross talks, recently role of Raf in the inhibition of apoptosis beside cell proliferation and survival, has also been identified in one study where the interaction of Raf-1 with ASK1 (apoptosis signal-regulating kinase 1) suggests a novel pro survival (antiapoptotic) mechanism for Raf-1 which is independent of MEK-ERK pathway (Chen et al., 2001). Unlike B-Raf, Raf1 is not essential for ERK activation so in the process of tumorigenesis it tends to interact with different proteins to allow cross-talk between signaling pathways such as include p21-activated kinase (PAK3), serine/threonine kinase 3 (STK3), and protein kinase C (PKC) (Huang et al., 2017). That might be the reason of non-significant suppression of MAP Kinase genes and insufficient evidence for apoptosis in cells which is just discussed ahead.

Therefore, further detailed studies appraising multiple gene expression analysis for relevant molecular pathways are warranted to explore exact mechanism of drugs combination.

We also dug out the potential of Sorafenib in inducing apoptosis of cancer cells which came out with insignificant results and so for Sorafenib with low dose of AZM. Literature supports the escape of cancer cells from apoptosis and formation of compensatory signaling pathways after being exposed to Sorafenib, are the possible reasons for its decreased efficacy (Cui et al., 2016). Sorafenib is a multi-kinase inhibitor of VEGFR, PDGFR, PI3K, MAPK, Raf etc. Although it had been after approved for the treatment of HCC but the overall efficacy of Sorafenib is not effectual as the tumor cells lose their sensitivity after long term exposure to antitumor drugs culminating into acquired resistance secondary to mechanisms such as addiction switching, compensatory pathway because of pathway loops or crosstalk, epithelialmesenchymal transition, cancer stem cells, disabling of pro-apoptotic signals, hypoxic environment (Zhai and Sun, 2013).

Nevertheless, more recently it was found in a study that Sorafenib exert its cytotoxic effect by the mechanism of ferroptosis which is necrosis in a regulated manner and quite different from apoptosis when it was tested in ten different cell lines including HCC cells (Huh7 and PLC/ PRF5). This study also established the role of Sorafenib as the first clinically approved drug that can induce ferroptosis (Lachaier et al., 2014; Cao et al., 2016). Hence, detailed researches must be conducted to study the underlying cancer cell death mechanisms of Sorafenib. 
Despite of significant data related to efficacy of AZM as proapoptotic agent (Zhou et al., 2012) our combination group didn't show any significant effects on apoptosis of HCC, the underlying reason may be lower dose of AZM used to employ the improved effects of sorafenib.

All of the above mentioned studies including present study, support that Sorafenib in combination with AZM poses enhanced anticancer activity with several probable mechanisms impeding growth and proliferation of cancer cells. Therefore their combination may be acceptable and justified, though mechanism of cytotoxicity the combinatorial treatment have employed, is highly reliant on dose and ratio of individual drugs.

\section{CONCLUSION}

The use of Sorafenib as the treatment option for HCC has been hampered by side effects subsequently resulting into discontinuation of therapy. The rationale behind combining Sorafenib with Azithromycin is to reduce the dose of Sorafenib in order to combat side effects and secondly to minimize the resistance faced by it. This in vitro study resulted in enhanced cytotoxicity of Sorafenib against hepatoma cells when it has been combined with AZM. With this combination the inhibition of proliferative MAPK pathway was found to be significant which could have been resulted in marked cell death at relatively lower dose but the cellular apoptosis turn out to be nonsignificant which highlights the need for assessing further molecular pharmacodynamical and pharmacokinetical basis behind the cytotoxicity exerted by the Sorafenib in the presence of AZM.

\section{Future recommendation}

Although drug repositioning has brought new insights into cancer research in terms of efficacy, it would be beneficial to conduct well-designed clinical researches that are able to test the combined efficacy of repurposed and renowned cytotoxic agent in order to achieve more useful transitional outcomes.

\section{Statement of conflict of interest}

The authors have declared no conflict of interests.

\section{REFERENCES}

Al-Darraji, A., Haydar, D., Chelvarajan, L., Tripathi, H., Levitan, B., Gao, E., Venditto, V.J., Gensel, J.C., Feola, D.J. and Abdel-Latif, A.J.P.O., 2018. Azithromycin therapy reduces cardiac inflammation and mitigates adverse cardiac remodeling after myocardial infarction: Potential therapeutic targets in ischemic heart disease. PLoS One, 13: e0200474. https://doi.org/10.1371/journal.pone.0200474

Asakura, E., Nakayama, H., Sugie, M., Zhao, Y.L., Nadai, M., Kitaichi, K., Shimizu, A., Miyoshi, M., Takagi, K. and Takagi, K.J.E.J.O.P., 2004. Azithromycin reverses anticancer drug resistance and modifies hepatobiliary excretion of doxorubicin in rats. Eur. J. Pharamcol., 484: 333-339. https:// doi.org/10.1016/j.ejphar.2003.11.035

Bell, S.J., Fam, C.M., Chlipala, E.A., Carlson, S.J., Lee, J.I., Rosendahl, M.S., Doherty, D.H. and Cox, G.N.J.B.C., 2008. Enhanced circulating half-life and antitumor activity of a site-specific pegylated interferon- $\alpha$ protein therapeutic. Bioconjug. Chem., 19: 299-305. https://doi.org/10.1021/bc070131q

Blivet-Van Eggelpoël, M.J., Chettouh, H., Fartoux, L., Aoudjehane, L., Barbu, V., Rey, C., Priam, S., Housset, C., Rosmorduc, O. and Desbois-Mouthon, C.J.J.O.H., 2012. Epidermal growth factor receptor and HER-3 restrict cell response to sorafenib in hepatocellular carcinoma cells. J. Hepatol., 57: 108115. https://doi.org/10.1016/j.jhep.2012.02.019

Cao, J.Y., Dixon, S.J.J.C. and Sciences, M.L., 2016. Mechanisms of ferroptosis. Cell Mol. Life Sci., 73: 2195-2209. https://doi.org/10.1007/s00018-0162194-1

Carlo-Stella, C., Locatelli, S.L., Giacomini, A., Cleris, L., Saba, E., Righi, M., Guidetti, A. and Gianni, A.M.J.P.O., 2013. Sorafenib inhibits lymphoma xenografts by targeting MAPK/ERK and AKT pathways in tumor and vascular cells. PLoS One, 8: e61603. https://doi.org/10.1371/journal. pone. 0061603

Chen, G., Nicula, D., Renko, K. and Derwahl, M.J.O.R., 2015. Synergistic anti-proliferative effect of metformin and sorafenib on growth of anaplastic thyroid cancer cells and their stem cells. Oncol. Rep., 33: 1994-2000. https://doi.org/10.3892/ or.2015.3805

Chen, K.F., Tai, W.T., Liu, T.H., Huang, H.P., Lin, Y.C., Shiau, C.W., Li, P.K., Chen, P.J. and Cheng, A.L.J.C.C.R., 2010a. Sorafenib overcomes TRAIL resistance of hepatocellular carcinoma cells through the inhibition of STAT3. Clin. Cancer Res., 16: 5189-5199. https://doi.org/10.1158/1078-0432. CCR-09-3389

Chen, K.F., Yu, H.C., Liu, T.H., Lee, S.S., Chen, P.J. and Cheng, A.L.J.J.O.H., 2010b. Synergistic interactions between sorafenib and bortezomib in hepatocellular carcinoma involve PP2A-dependent Akt inactivation. J. Hepatol., 52: 88-95. https://doi. org/10.1016/j.jhep.2009.10.011 
Csoti, I., Herbst, H., Urban, P., Woitalla, D. and Wüllner, U.J., 2019. Polypharmacy in Parkinson's disease: Risks and benefits with little evidence. $J$. Neural. Transm. (Vienna), 126: 871-878. https:// doi.org/10.1007/s00702-019-02026-8

Cui, S.X., Shi, W.N., Song, Z.Y., Wang, S.Q., Yu, X.F., Gao, Z.H. and Qu, X.J.., 2016. Des-gammacarboxy prothrombin antagonizes the effects of Sorafenib on human hepatocellular carcinoma through activation of the Raf/MEK/ERK and $\mathrm{PI} 3 \mathrm{~K} / \mathrm{Akt} / \mathrm{mTOR}$ signaling pathways. Oncotarget, 7: 36767. https://doi.org/10.18632/oncotarget.9168

Decoster, M.A., 2007. The nuclear area factor (NAF): A measure for cell apoptosis using microscopy and image analysis. In: Modern research and educational topics in microscopy (Eds. A. MéndezVilas and J. Díaz). FORMATEX, pp. 378-84.

Feng, R., Gong, J., Wu, L., Wang, L., Zhang, B., Liang, G., Zheng, H. and Xiao, H.J., 2017. MAPK and Hippo signaling pathways crosstalk via the RAF-1/ MST-2 interaction in malignant melanoma. Oncol. Rep., 38: 1199-1205. https://doi.org/10.3892/ or.2017.5774

Ferdousi, S.A., Akhter, A., Nahar, K. and Islam, A.J., 2017. High dose methotrexate and leucovorin rescue therapy in childhood malignancies: Experience in resource-limited country. Bangladesh J. Child Hlth., 41: 15-23. https://doi.org/10.3329/bjch. v41i1.33630

Gauthier, A. and Ho, M.J.H.R., 2013. Role of sorafenib in the treatment of advanced hepatocellular carcinoma: An update. Hepatol. Res., 43: 147-154. https://doi.org/10.1111/j.1872-034X.2012.01113.x

Gedaly, R., Angulo, P., Hundley, J., Daily, M.F., Chen, C. and Evers, B.M., 2012. PKI-587 and sorafenib targeting PI3K/AKT/mTOR and Ras/Raf/ MAPK pathways synergistically inhibit HCC cell proliferation. Surg. Res., 176: 542-548. https://doi. org/10.1016/j.jss.2011.10.045

Greco, F. and Vicent, M.J., 2009. Combination therapy: opportunities and challenges for polymer-drug conjugates as anticancer nanomedicines. $A d v$. Drug Deliv. Rev., 61: 1203-1213. https://doi. org/10.1016/j.addr.2009.05.006

Gupta, S. and Vyas, S.P., 2007. Development and characterization of amphotericin $\mathrm{B}$ bearing emulsomes for passive and active macrophage targeting. J. Drug Target, 15: 206-217. https://doi. org/10.1080/10611860701195395

Hepatology, E.A., 2018. EASL clinical practice guidelines: Management of hepatocellular carcinoma. J. Hepatol., 69: 182-236. https://doi. org/10.1016/j.jhep.2018.03.019

Hirasawa, K., Moriya, S., Miyahara, K., Kazama, H., Hirota, A., Takemura, J., Abe, A., Inazu, M., Hiramoto, M. and Tsukahara, K.J., 2016. Macrolide antibiotics exhibit cytotoxic effect under amino acid-depleted culture condition by blocking autophagy flux in head and neck squamous cell carcinoma cell lines. PLoS One, 11: e0164529. https://doi.org/10.1371/journal.pone.0164529

Huang, Y., Guo, X.X., Han, B., Zhang, X.M., An, S., Zhang, X.Y., Yang, Y., Liu, Y., Hao, Q. and Xu, T.R., 2017. Decoding the full picture of Rafl function based on its interacting proteins. Target Oncol., 8: 68329. https://doi.org/10.18632/oncotarget.19353

Islam, S., Mokhtari, R., Akbari, P., Hatina, J., Yeger, H. and Farhat, W.J., 2016. Simultaneous targeting of bladder tumor growth, survival, and epithelial-to-mesenchymal transition with a novel therapeutic combination of acetazolamide (AZ) and sulforaphane (SFN). Target Oncol., 11: 209-227. https://doi.org/10.1007/s11523-015-0386-5

Keating, G.M. and Santoro, A.J.D., 2009. Sorafenib: A review of its use in advanced hepatocellular carcinoma. Drugs, 69: 223-240. https://doi. org/10.2165/00003495-200969020-00006

Lachaier, E., Louandre, C., Godin, C., Saidak, Z., Baert, M., Diouf, M., Chauffert, B. and Galmiche, A.J., 2014. Sorafenib induces ferroptosis in human cancer cell lines originating from different solid tumors. Anticancer Res., 34: 6417-6422.

Lamb, R., Ozsvari, B., Lisanti, C.L., Tanowitz, H.B., Howell, A., Martinez-Outschoorn, U.E., Sotgia, F. and Lisanti, M.P., 2015. Antibiotics that target mitochondria effectively eradicate cancer stem cells, across multiple tumor types: Treating cancer like an infectious disease. Oncotarget, 6: 4569. https://doi.org/10.18632/oncotarget.3174

Le Grazie, M., Biagini, M.R., Tarocchi, M., Polvani, S. and Galli, A.J., 2017. Chemotherapy for hepatocellular carcinoma: The present and the future. World J. Hepatol,, 9: 907. https://doi. org/10.4254/wjh.v9.i21.907

Liang, Y., Zheng, T., Song, R., Wang, J., Yin, D., Wang, L., Liu, H., Tian, L., Fang, X. and Meng, X.J.H., 2013. Hypoxia-mediated sorafenib resistance can be overcome by EF24 through Von Hippel-Lindau tumor suppressor-dependent HIF-1 $\alpha$ inhibition in hepatocellular carcinoma. Hepatology, 57: $1847-$ 1857. https://doi.org/10.1002/hep.26224

Llovet, J.M., Ricci, S., Mazzaferro, V., Hilgard, P., Gane, E., Blanc, J.F., de Oliveira, A.C., Santoro, A., Raoul, J.L. and Forner, A.J., 2008. Sorafenib 
in advanced hepatocellular carcinoma. N. Engl. J. Med., 359: 378-390. https://doi.org/10.1056/ NEJMoa0708857

Luo, J., Li, Y.N., Wang, F., Zhang, W.M. and Geng, X.J., 2010. S-adenosylmethionine inhibits the growth of cancer cells by reversing the hypomethylation status of c-myc and H-ras in human gastric cancer and colon cancer. Int. J. biol. Sci., 6: 784. https:// doi.org/10.7150/ijbs.6.784

Mokhtari, R.B., Homayouni, T.S., Baluch, N., Morgatskaya, E., Kumar, S., Das, B. and Yeger, H.J., 2017. Combination therapy in combating cancer. Oncotarget, 8: 38022. https://doi.org/10.18632/ oncotarget. 16723

Mokhtari, R.B., Kumar, S., Islam, S.S., Yazdanpanah, M., Adeli, K., Cutz, E. and Yeger, H.J., 2013. Combination of carbonic anhydrase inhibitor, acetazolamide, and sulforaphane, reduces the viability and growth of bronchial carcinoid cell lines. BMC Cancer, 13: 378. https://doi. org/10.1186/1471-2407-13-378

Moriya, S., Che, X.F., Komatsu, S., Abe, A., Kawaguchi, T., Gotoh, A., Inazu, M., Tomoda, A. and Miyazawa, K.J., 2013. Macrolide antibiotics block autophagy flux and sensitize to bortezomib via endoplasmic reticulum stress-mediated $\mathrm{CHOP}$ induction in myeloma cells. Int. J. Oncol., 42: 1541-1550. https://doi.org/10.3892/ijo.2013.1870

Muniz, F.W., de Oliveira, C.C., de Sousa Carvalho, R., Moreira, M.M.S.M., de Moraes, M.E.A. and Martins, R.S., 2013. Azithromycin: A new concept in adjuvant treatment of periodontitis. Eur. J. Pharmacol., 705: 135-139. https://doi. org/10.1016/j.ejphar.2013.02.044

Omata, M., Cheng, A.L., Kokudo, N., Kudo, M., Lee, J. M., Jia, J., Tateishi, R., Han, K.H., Chawla, Y.K. and Shiina, S.J., 2017. Asia-Pacific clinical practice guidelines on the management of hepatocellular carcinoma: A 2017 update. Hepatol. Int., 11: 317370. https://doi.org/10.1007/s12072-017-9799-9

Pang, T., Benicky, J., Wang, J., Orecna, M., SanchezLemus, E. and Saavedra, J.M., 2012. Telmisartan ameliorates lipopolysaccharide-induced innate immune response through peroxisome proliferatoractivated receptor- $\gamma$ activation in human monocytes. J. Hypertens., 30: 87. https://doi.org/10.1097/ HJH.0b013e32834dde5f

Partridge, A. H., Burstein, H.J. and Winer, E.P., 2001. Side effects of chemotherapy and combined chemohormonal therapy in women with early-stage breast cancer. J. natl. Cancer Inst. Monogr., 2001: 135-142. https://doi.org/10.1093/oxfordjournals. jncimonographs.a003451

Pritchard, J.R., Bruno, P.M., Gilbert, L.A., Capron, K.L., Lauffenburger, D.A. and Hemann, M.T., 2013. Defining principles of combination drug mechanisms of action. Proc. natl. Acad. Sci. U.S.A., 110: E170-E179. https://doi.org/10.1073/ pnas. 1210419110

Pule, C.M., Sampson, S.L., Warren, R.M., Black, P.A., van Helden, P.D., Victor, T.C. and Louw, G.E., 2016. Efflux pump inhibitors: Targeting mycobacterial efflux systems to enhance TB therapy. J. Antimicrob. Chemother., 71: 17-26. https://doi.org/10.1093/jac/dkv316

Qiao, X., Wang, X., Shang, Y., Li, Y. and Chen, S.Z., 2018. Azithromycin enhances anticancer activity of TRAIL by inhibiting autophagy and up-regulating the protein levels of DR $4 / 5$ in colon cancer cells in vitro and in vivo. Cancer Commun. (Lond.), 38: 43. https://doi.org/10.1186/s40880-018-0309-9

Safe, S., Nair, V. and Karki, K.J., 2018. Metformininduced anticancer activities: Recent insights. Biol. Chem., 399: 321-335. https://doi.org/10.1515/hsz2017-0271

van Malenstein, H., Dekervel, J., Verslype, C., van Cutsem, E., Windmolders, P., Nevens, F. and van Pelt, J.J., 2013. Long-term exposure to sorafenib of liver cancer cells induces resistance with epithelialto-mesenchymal transition, increased invasion and risk of rebound growth. Cancer Lett., 329: 74-83. https://doi.org/10.1016/j.canlet.2012.10.021

Wallace, M.C., Preen, D., Jeffrey, G.P. and Adams, L.A. 2015. The evolving epidemiology of hepatocellular carcinoma: A global perspective. Expert Rev. Gastroenterol. Hepatol., 9: 765-779. https://doi.or g/10.1586/17474124.2015.1028363

Wang, S., Ghosh, R.N. and Chellappan, S.P., 1998. Raf- 1 physically interacts with $\mathrm{Rb}$ and regulates its function: A link between mitogenic signaling and cell cycle regulation. Mol. Cell Biol., 18: 74877498. https://doi.org/10.1128/MCB.18.12.7487

Zehra, D., Memon, Z., Moin, K., Usman, S., Zafar, U. and Zahid, N.J., 2019. Antitumor potential of antimicrobials: An anticipated armour for hepatocellular carcinoma. J. Adv. Med. med. Res., 30: 1-8. https://doi.org/10.9734/jammr/2019/ v30i730212

Zhai, B. and Sun, X.Y., 2013. Mechanisms of resistance to sorafenib and the corresponding strategies in hepatocellular carcinoma. World J. Hepatol., 5: 345. https://doi.org/10.4254/wjh.v5.i7.345

Zhou, X., Zhang, Y., Li, Y., Hao, X., Liu, X. and Wang, Y.J.C., 2012. Azithromycin synergistically 
enhances anti-proliferative activity of vincristine in cervical and gastric cancer cells. Cancers (Basel), 4: 1318-1332. https://doi.org/10.3390/ cancers 4041318

Zhu, A.X., Kudo, M., Assenat, E., Cattan, S., Kang, Y.K., Lim, H.Y., Poon, R.T., Blanc, J.F., Vogel, A. and Chen, C.L., 2014. Effect of everolimus on survival in advanced hepatocellular carcinoma after failure of sorafenib: the EVOLVE-1 randomized clinical trial. J. Am. med. Assoc., 312: 57-67. https://doi. org/10.1001/jama.2014.7189

Zhu, Y.J., Zheng, B., Wang, H.Y. and Chen, L.J., 2017.
New knowledge of the mechanisms of sorafenib resistance in liver cancer. Acta Pharmacol. Sin., 38: 614-622. https://doi.org/10.1038/aps.2017.5

Zimmermann, P., Ziesenitz, V.C., Curtis, N. and Ritz, N.J., 2018. The immunomodulatory effects of macrolides-A systematic review of the underlying mechanisms. Front. Immunol., 9: 302. https://doi. org/10.3389/fimmu.2018.00302

Zimmermann, S. and Moelling, K.J.S., 1999. Phosphorylation and regulation of Raf by Akt (protein kinase B). Science, 286: 1741-1744. https://doi.org/10.1126/science.286.5445.1741 